\title{
Risk Factors for Antimicrobial Use on Irish Pig Farms
}

\author{
Lorcan $\mathrm{O}^{\prime}$ Neill 1,2,*, Julia Adriana Calderón Díaz ${ }^{1}$ (D), Maria Rodrigues da Costa ${ }^{1,2,+}$ (D), Sinnead Oakes ${ }^{3, \ddagger}$, \\ Finola C. Leonard ${ }^{2}$ and Edgar García Manzanilla ${ }^{1,2}$ (D)
}

1 Pig Development Department, Teagasc, The Irish Food and Agriculture Authority, Moorepark, Fermoy, Co Cork P61 C996, Ireland; Julia.CalderonDiaz@teagasc.ie (J.A.C.D.); maria.costa@sruc.ac.uk (M.R.d.C.); egmanzanilla@gmail.com (E.G.M.)

2 School of Veterinary Medicine, University College Dublin, Belfield, Dublin 4 D04 W6F6, Ireland; nola.leonard@ucd.ie

3 School of Public Health, University College Cork, Cork T12 K8AF, Ireland; sinnead.oakes@agriculture.gov.ie

* Correspondence: lorcan.oneill@ucdconnect.ie

+ Current address: Epidemiology Research Unit, Department of Veterinary and Animal Science, Northern Faculty, Scotland's Rural College, An Lòchran, 10 Inverness Campus, Inverness, Scotland IV2 5NA, UK.

$\ddagger$ Current address: Department of Agriculture, Food and the Marine, Dublin Port, Dublin D02 WK12, Ireland.

check for updates

Citation: O’Neill, L.; Calderón Díaz, J.A.; Rodrigues da Costa, M.; Oakes, S.; Leonard, F.C.; Manzanilla, E.G. Risk Factors for Antimicrobial Use on Irish Pig Farms. Animals 2021, 11, 2828. https://doi.org/10.3390/ani11102828

Academic Editor: Sangeeta Rao

Received: 1 September 2021

Accepted: 25 September 2021

Published: 28 September 2021

Publisher's Note: MDPI stays neutral with regard to jurisdictional claims in published maps and institutional affiliations.

Copyright: (c) 2021 by the authors. Licensee MDPI, Basel, Switzerland. This article is an open access article distributed under the terms and conditions of the Creative Commons Attribution (CC BY) license (https:// creativecommons.org/licenses/by/ $4.0 /)$.
Simple Summary: Antimicrobial resistance (AMR) is a major threat to public health. There are concerns that antimicrobial use (AMU) in agriculture has a role in the development of AMR. Pigs are one of the main consumers of veterinary antimicrobials and a better understanding of the drivers for AMU in this sector will help in efforts to reduce use. The aim of this study was to investigate the associations between antimicrobial use, farm characteristics, biosecurity, the presence of respiratory disease on the farm and health management practices on Irish pig farms. Farms that manufactured their feed on-site had lower total AMU than farms that purchased their feed from a feed mill. Higher levels of lung abscesses and pericarditis (inflammation of the lining around the heart), both indicators of respiratory disease, were associated with increased AMU. Higher levels of pericarditis were also associated with increased use of critically important antimicrobials. Farms vaccinating against swine influenza also had higher AMU. Farms that administered prophylactic antimicrobial treatments to piglets had higher use of individual treatments and critically important antimicrobials. The results from this study show that prophylaxis and respiratory disease are the main drivers of AMU on Irish pig farms. These findings highlight areas of farm management where interventions may aid in reducing AMU on Irish pig farms.

Abstract: The threat to public health posed by antimicrobial resistance in livestock production means that the pig sector is a particular focus for efforts to reduce antimicrobial use (AMU). This study sought to investigate the risk factors for AMU in Irish pig production. Antimicrobial use data were collected from 52 farrow-to-finish farms. The risk factors investigated were farm characteristics and performance, biosecurity practices, prevalence of pluck lesions at slaughter and serological status for four common respiratory pathogens and vaccination and prophylactic AMU practices. Linear regression models were used for quantitative AMU analysis and risk factors for specific AMU practices were investigated using logistic regression. Farms that milled their own feed had lower total AMU $(p<0.001)$, whereas higher finisher mortality $(p=0.043)$ and vaccinating for swine influenza $(p<0.001)$ increased AMU. Farms with higher prevalence of pericarditis $(p=0.037)$ and lung abscesses $(p=0.046)$ used more group treatments. Farms with higher prevalence of liver milk spot lesions $(p=0.018)$ and farms practising prophylactic AMU in piglets $(p=0.03)$ had higher numbers of individual treatments. Farms practising prophylactic AMU in piglets $(p=0.002)$ or sows $(p=0.062)$ had higher use of cephalosporins and fluoroquinolones. This study identified prophylactic use and respiratory disease as the main drivers for AMU in Irish pig production. These findings highlight areas of farm management where interventions may aid in reducing AMU on Irish pig farms.

Keywords: antimicrobial use; biosecurity; Ireland; pigs; respiratory disease; risk factors 


\section{Introduction}

Antimicrobial resistance (AMR) is a continued and increasing threat to global public health [1]. Improved antimicrobial stewardship and ultimately reduced antimicrobial use (AMU) are key components of various action plans to mitigate this threat [2,3]. Antimicrobial use in livestock production is a focus of concern because it accounts for a large proportion of global AMU [4] and animals may act as a reservoir for AMR pathogens and AMR genes [5]. Furthermore, the literature suggests that restricting AMU in livestock can reduce AMR in animals and humans [6].

The pig sector is a major consumer of veterinary antimicrobials (AMs) and ranks highest in several countries [7-9]. In pig production, AMs are primarily administered as group treatments to piglets post-weaning, via oral routes of administration and more often at strategic times in the production cycle [10,11]. A better understanding of the risk factors for this AMU will aid in efforts to reduce it. Antimicrobials are used for the treatment, prevention and control of infectious disease [12-14], and respiratory and gastrointestinal disease are the major indications for use $[11,15,16]$. Therefore, it would be expected that disease burden is the primary driver for AMU. However, the relationship between disease burden and AMU is not well-characterised [17,18].

Farm characteristics and management practices such as herd size [19-21], proximity to other pig farms $[20,22,23]$, raising finisher pigs on specialised farms (which may use multiple suppliers) [20,21], increased farrowing rhythm and longer suckling period [24] can also influence AMU. Furthermore, higher levels of biosecurity [24,25] and implementing some specific biosecurity practices, such as provision of changing facilities [26] and provision of boots to visitors [22], are also associated with reduced AMU. Vaccination is considered a key tool in disease control and in reducing reliance on AMU [27-30]. However, despite effectiveness in field studies [31-33], vaccination has been associated with increased AMU in several studies $[17,24,30,34,35]$. Finally, socio-economic and demographic factors such as age, gender, education or years of experience [36] and attitudes to AMR [37] can influence on farm AMU, although their relative importance appears to differ depending on nationality [17]. In general, pig farmers perceive AMs as an effective and cost-efficient tool in disease management $[30,38-40]$ and, at least in the past, were poorly aware or unconcerned about the risks of AMR [38,39,41].

There is little information about the factors associated with the choice of AM treatment, i.e., active ingredient and route of administration, on pig farms [42]. The various AMs have specific indications for use, and many are licensed to treat more than one condition. There are official national guidelines dictating which AMs should be used for specific conditions $[43,44]$. However, they are not always followed $[15,45]$ and there can be notable variation in choice of treatment for the same condition [46]. A better understanding of the reasons behind such choices may aid in improving antimicrobial stewardship and would be especially useful for the highest priority critically important antimicrobials (HP CIA) which are most important to public health.

According to Collineau et al., the relative importance of risk factors associated with AMU varies between countries [17]. In Ireland, pig production accounts for approximately $40 \%$ of veterinary AM consumption, with prophylactic administration of medicated feed being the dominant practice [47], but the drivers for this use on Irish farms have not been studied previously. This study aimed to explore the risk factors for AMU in a cohort of Irish farrow-to-finish farms using AMU, biosecurity, respiratory disease and farm management data. A further aim was to investigate risk factors for specific AMU practices, namely the choice of AM class and route of administration.

\section{Materials and Methods}

\subsection{Farm Selection}

This cross-sectional study was conducted on a sample of 52 Irish pig farms to investigate risk factors for AMU. The risk factors investigated were grouped as follows: biosecurity practices; farm management practices, including vaccination; farm status and 
prevalence of respiratory disease; and farm performance indicators. The study farms were part of a larger cohort of farms that participated in two separate but closely related projects, investigating (1) antimicrobial use and (2) respiratory disease, which were conducted from February 2016 to September 2018. All participants were clients of the Teagasc (Teagasc, the Agriculture and Food Development Authority, https:/ /www.teagasc.ie/animals/pigs/ accessed on 20 September 2021) farm advisory service, which is available to all Irish pig farms. In 2017, the Teagasc farm advisory service included 107 pig farms, representing over 77,000 sows (approximately 50\% of the national herd) [48]. All client farms were invited to participate in both projects on a voluntary basis, and the 52 farms in this study represent those that provided sufficient data to both the AMU and the respiratory disease projects.

\subsection{Farm Production and Performance}

The study farms submit their production data to the Teagasc e-Profit Monitor (ePM) database quarterly. The following indicators for the 2016 calendar year were extracted from the ePM database: herd size, piglet, weaner and finisher mortality, average age at weaning, at transfer to finisher and at slaughter (which were used to calculate length of stay in the weaner and finisher stages), average daily gain (ADG) and feed conversion ratio (FCR).

\subsection{Antimicrobial Use}

Antimicrobial use data for the 2016 calendar year were collected for each farm by means of farm visits conducted from September 2017 to September 2018, as previously described by $\mathrm{O}^{\prime} \mathrm{Neill}$ et al. [47]. In short, details of AMU in medicated feed regarding the diets and age groups treated and the AMs used were provided by the farmers. The amounts of AMs in oral remedies other than premix (i.e., not for medicated feed) and injectable preparations were determined using invoice and or prescription records. Feed consumption data (to calculate amount of medicated feed) and population data were extracted from the ePM database. Treatment incidence (TI), which represents the percentage of pigs in a stage of production treated with a dose of AM each day (or equivalently, the percentage time of the period at risk for which a pig was treated) [49], was calculated for each AM and route of administration in each stage of production (piglet, weaner and finisher). The TI was calculated using the formula adapted by Sarrazin et al. [11] and the Defined Daily Dose (DDD ${ }_{\text {vet }}$ ) for each AM, as assigned by the European Medicines Agency (EMA) [50], and standard weights for each age group, as proposed by the European Surveillance of Veterinary Antimicrobial Consumption (ESVAC) project [51]:

$$
\mathrm{TI}_{\mathrm{DDDvet}}=\frac{\text { amount of antimicrobial used }(\mathrm{mg})}{\mathrm{DDD}_{\text {vet }}(\mathrm{mg} / \mathrm{kg}) \times \mathrm{kg} \text { of animal at risk }(\mathrm{kg}) \times \text { number of days at risk }} \times 100 \text { animals at risk }
$$

The TI values for piglets, weaners and finishers were then combined to calculate the standardised TI200 indicator, which represents AMU for the entire rearing period, using the formula defined by Sjölund et al. [10]:

$\mathrm{TI} 200=\frac{\mathrm{TI}_{\text {piglet }} \times \text { suckling period }+\mathrm{TI}_{\text {weaner }} \times \text { weaner period }+\mathrm{TI}_{\text {finisher }} \times \text { fininshing period }}{\text { total rearing period }} \times \frac{200(\text { standard life span })}{\text { total rearing period }}$

Information on which vaccinations were used on the farm and whether the farm administered prophylactic AM treatments (other than in medicated feed) in the different production stages (by any route of administration) was also collected for each farm.

\subsection{Biosecurity Assessment and Farm Management Practices}

Biosecurity practices were assessed using the Biocheck.UGent ${ }^{\mathrm{TM}}$ (https://bioche ck.ugent.be/en accessed on 20 September 2021) questionnaire, which was completed during the course of farm visits conducted between February and May 2016 [52]. The Biocheck.UGent ${ }^{\mathrm{TM}}$ questionnaire consists of 109 closed questions which assess various biosecurity measures and farm management practices. Questions on farm characteristics 
do not contribute to the biosecurity score and include the age of the oldest and youngest buildings, the number of employees and the experience of the farm manager/owner. Information on whether the farm milled its own feed or purchased from an external feed mill was also collected. Biosecurity-related questions are grouped into six external biosecurity categories and six internal biosecurity categories. Each question contributes a weighted score to its category and each category contributes a weighted score to the external or internal biosecurity score. The overall biosecurity score is computed as the average of the external and internal biosecurity scores. Scores range from 0 to 100, where 0 indicates the absence of biosecurity and 100 represents perfect biosecurity. The questionnaire for pigs is described in detail by Laanen et al. [25]. The scores for each category as well as the internal, external and overall biosecurity scores were used in the statistical analysis.

\subsection{Respiratory Disease Status and Farm Prevalence}

Data on disease status and prevalence of pluck (lungs, heart and liver) lesions were collected from November 2017 to April 2018, as previously described by Rodrigues da Costa et al. [53]. Disease status for Influenza A virus (IAv), Porcine reproductive and respiratory syndrome virus (PRRSv), Mycoplasma hyopneumoniae (Mhyo) and Actinobacillus pleuropneumoniae (APP) was determined using serological testing. Thirty-two samples per farm were collected and processed at the Blood Testing Laboratory of the Department of Food, Agriculture and the Marine (Cork, Ireland). Serum was separated from the samples and stored at $-80{ }^{\circ} \mathrm{C}$ until further analysis. For analysis, all 32 samples were used for detection of IAv and PRRSv (allowing for a minimum within-herd prevalence of $10 \%$, $\alpha=0.05$ ), while 16 samples were used for detection of Mhyo and APP (allowing for a minimum within-herd prevalence of $18 \%, \alpha=0.05$ ). The seroprevalence of antibodies against IAv, PRRSv, Mhyo and APP were determined using the respective IDEXX ELISA kits, for the four respiratory pathogens: Influenza A Ab Test, PRRS X3 Ab Test, HerdChek Mycoplasma hyopneumoniae Ab Test and APP-ApxIV Ab Test (IDEXX, Hoofddorp, The Netherlands), according to the manufacturer's instructions. Farms were considered positive if at least one sample tested positive by the relevant serological test.

All pluck examinations were carried out by a single trained veterinarian. Lungs were removed from the carcass by abattoir personnel and scored in the evisceration line for pneumonic lesions using the method described by Madec and Derrien [54]. Pleurisy in the dorsocaudal lobes was scored using a modified version of the Slaughterhouse Pleurisy Evaluation System (SPES) $[55,56]$ with a 4-point scale, in which $0=$ no pleurisy, $2=$ focal lesions in one lobe, $3=$ bilateral adhesions or unilateral lesions affecting more than $1 / 3$ of one diaphragmatic lobe and $4=$ extensive lesions affecting more than $1 / 3$ of both diaphragmatic lobes (SPES score $=1$ corresponds to cranial pleurisy and is not used in the modified SPES scoring system). The prevalence of dorsocaudal pleurisy, i.e., lesions with SPES score $\geq 2$, and the prevalence of moderate or severe dorsocaudal pleurisy, i.e., lesions with SPES score 3 or 4 , were used for statistical analysis. Additionally, scars, indicative of healing pneumonic lesions from previous infection, cranial pleurisy (adhesions between lobes, on the surface of the apical and cardiac lobe, and/or adhesions between the lung and the heart), pericarditis (expansion of the pericardial cavity with inflammatory exudate [57]), lung abscesses and liver spots (indicative of transhepatic migration of the larvae of Ascaris suum [58]) were recorded as present or absent.

\subsection{Data Processing and Statistical Analysis}

All data were entered into a Microsoft ${ }^{\circledR}$ Excel 365 (Microsoft Corporation, Redmond, WA, USA) spreadsheet. Calculations and statistical analyses were carried out using Microsoft ${ }^{\circledR}$ Excel and $\mathrm{R}$ version 3.4.2 [59]. Data visualisation was carried out using the ggplot2 and VennDiagram packages in R [60,61]. Two separate analyses were carried out to investigate risk factors associated with (1) quantitative AMU and (2) AMU practices.

For the quantitative AMU analysis, the outcome variables were total TI200 for group oral treatments administered ( $\left.\mathrm{TI}_{\text {group }}\right)$, total $\mathrm{TI} 200$ for individual treatments $\left(\mathrm{TI}_{\text {individual }}\right)$, 
combined TI200 for ceftiofur and fluoroquinolones (TI ceflq $_{\text {) }}$ and total TI200 for all routes of administration $\left(\mathrm{TI}_{\text {total }}\right)$. Variables were checked for normality by examining the quartilequartile plot and by using the Shapiro-Wilks test. The four outcome variables were not normally distributed and thus, a log transformation was applied to approach a normal distribution. The transformation of $\mathrm{TI}_{\text {group }}$ and $\mathrm{TI}_{\text {ceflq }}$ required the addition of a constant $(1$ and 0.01 , respectively) to account for farms with zero AMU in these categories. Collinearity among the predictor variables was checked using Spearman rank correlations for continuous variables, Wilcoxon rank sum test for continuous and categorical variables and chi squared or Fisher's exact test for categorical variables. Categorical predictor variables (all were binary in this dataset) with less than 10 farms in either category were excluded from further analysis. For each outcome variable, the associations with each of the predictor variables were first assessed using univariable linear regression models. A multivariable linear regression model was then created using predictor variables with $p \leq 0.25$ in the univariate analysis. Where there was collinearity among the predictor variables (Spearman rho $>0.7$ or $p$-value of chi-square/Fisher tests $\leq 0.05$ ), the variable with the strongest association in the univariable model or the one with the most biological significance was selected. Alpha level for determination of significance was 0.05 and trends are discussed between 0.05 and 0.1. The model was then refined using manual backward selection, removing the predictor variable with the highest $p$-value until all remaining variables had a $p \leq 0.1$.

Associations between specific AMU practices and the predictor variables were investigated using logistic regression. Here, the outcome variables were each combination of AM class and the two main routes of administration: oral group treatments (eight outcome variables) and individual treatments (eight outcome variables). Collinearity among the predictor variables was checked as per the quantitative AMU analysis and categorical variables with less than 10 farms in either category were excluded from the analysis. Univariable associations between each outcome variable and predictor variable were assessed using chi-squared or Fisher's exact test along with the respective odds ratio if the predictor variable was categorical, and univariable logistic regression for continuous variables. Thresholds for significance and tendency were set as for the linear regression analysis. Multivariable logistic regression models were then created using predictor variables with $p \leq 0.25$ in the univariate analysis and refined using manual backward selection until all remaining variables had a $p \leq 0.1$.

\section{Results}

A summary of the farm characteristics and production data is presented in Table S1. The 52 farms had a combined population of 38,764 sows and thus represented approximately $29 \%$ of the national herd in 2016. The median herd size was 650 sows (range: 113-2354) and all farms operated a farrow-to-finish system which accounts for virtually all pig production in Ireland [62]. Twenty-two farms (42.3\% of sample) practised home milling, whereby at least one diet was manufactured on the farm, while the remaining farms purchased all feed. Antimicrobial use expressed as TI200 is summarised in Table 1. The median TI200 was 14.2 (range: $0.2-169.1$ ). Oral group treatments accounted for $93.3 \%$ of consumption $(81.5 \%$ via medicated feed, $11.6 \%$ via water) and were administered on all but two farms. Provision of medicated feed to piglets via starter and/or link diets during the first 7 to 21 days post-weaning was standard practice on 44 farms ( $84.6 \%$ of sample), and 27 farms (51.9\% of sample) provided medicated feed in the subsequent diets (see O'Neill et al. [47] for a full description). All farms administered individual AM treatments. 
Table 1. Antimicrobial use on 52 Irish farrow-to-finish pig farms during 2016 summarised by mode of treatment. The number of farms using each antimicrobial class and the mean and median treatment incidence (TI200) for each mode of treatment is shown.

\begin{tabular}{|c|c|c|c|}
\hline Antimicrobial Class & Farms with Use & Mean (SD) & Median (Range) \\
\hline \multicolumn{4}{|l|}{ Oral group treatments } \\
\hline Tetracylines & $38(73.1 \%)$ & $7.7(12)$ & $1.2(0-49.1)$ \\
\hline Potentiated sulphonamides & $17(32.7 \%)$ & $6.6(22.8)$ & $0(0-150.1)$ \\
\hline Penicillins & $36(69.2 \%)$ & $2.7(5.5)$ & $0.9(0-29.7)$ \\
\hline Macrolides & $23(44.2 \%)$ & $2.3(4.4)$ & $0(0-23.6)$ \\
\hline Lincosamides & $10(19.2 \%)$ & $0.1(0.5)$ & $0(0-2.9)$ \\
\hline Amphenicols & $7(13.5 \%)$ & $0.1(0.4)$ & $0(0-2.5)$ \\
\hline Aminoglycosides & $27(51.9 \%)$ & $0.5(1.3)$ & $0(0-8.9)$ \\
\hline Aminocyclitols * & $10(19.2 \%)$ & $0.1(0.3)$ & $0(0-1.9)$ \\
\hline Polymyxins & $13(25 \%)$ & $0.8(2.6)$ & $0(0-13)$ \\
\hline Total oral group treatments ( $\mathrm{TI}_{\text {group }}$ ) & $50(96.2 \%)$ & $21(28.5)$ & $13.3(0-167.8)$ \\
\hline \multicolumn{4}{|l|}{ Individual treatments } \\
\hline Tetracyclines & $22(42.3 \%)$ & $0.1(0.2)$ & $0(0-0.9)$ \\
\hline Potentiated sulphonamides & $8(15.4 \%)$ & $0.1(0.3)$ & $0(0-2.2)$ \\
\hline Penicillins & $52(100 \%)$ & $0.6(0.6)$ & $0.4(0-2)$ \\
\hline Macrolides & $18(34.6 \%)$ & $0.2(0.6)$ & $0(0-4)$ \\
\hline Lincosamides & $21(40.4 \%)$ & $0(0)$ & $0(0-0.2)$ \\
\hline Amphenicols & $5(9.6 \%)$ & $0(0)$ & $0(0-0.3)$ \\
\hline Aminoglycosides & $14(26.9 \%)$ & $0(0.1)$ & $0(0-0.3)$ \\
\hline Aminocyclitols & $23(44.2 \%)$ & $0(0)$ & $0(0-0.2)$ \\
\hline Fluoroquinolones & $45(86.5 \%)$ & $0.2(0.3)$ & $0.1(0-1.2)$ \\
\hline Cephalosporins & $12(23.1 \%)$ & $0.2(0.8)$ & $0(0-4.6)$ \\
\hline Pleuromutilins & $1(1.9 \%)$ & $0(0)$ & $0(0-0)$ \\
\hline Total individual treatments $\left(\mathrm{TI}_{\text {individual }}\right)$ & $52(100 \%)$ & $1.5(1.6)$ & $1.1(0.1-11.4)$ \\
\hline Total antimicrobial use $\left(\mathrm{TI}_{\text {total }}\right)$ & $52(100 \%)$ & $22.5(28.6)$ & $14.2(0.2-169.1)$ \\
\hline Cephalopsorin and/or fluoroquinolone use $\left(\mathrm{TI}_{\text {ceflq }}\right)$ & $47(90.4 \%)$ & $0.5(0.9)$ & $0.2(0-5.8)$ \\
\hline
\end{tabular}

* Aminocyclitols in group treatments were used in combination with lincosamides. Legend: TI-treatment incidence.

The breakdown of AMU by AM class and stage of production is shown in Figure 1. The most frequently used AM classes overall were tetracyclines, potentiated sulphonamides, penicillins and macrolides, accounting for $34.8 \%, 32.5 \%, 12.9 \%$ and $11.5 \%$ of AMU, respectively. Fluoroquinolones and cephalosporins accounted for $1.8 \%$ of AMU and were used on $90.4 \%$ of farms. Weaner pigs received $80.5 \%$ of all doses, but piglets accounted for $65 \%$ of individual treatments. The biosecurity scores for the study farms are summarised in Table S2. Farms typically had higher scores in external biosecurity (median 79.5 (range: 62-94)) than in internal biosecurity (60 (range: 29-80)). The category with the highest score was 'purchase of animals and semen', where 49 farms (94.2\% of sample) had a perfect score, while the lowest scoring category was 'cleaning and disinfection' (median 38 (range: 0-95)). The farm vaccination and AM prophylaxis practices are summarised in Table S3. All farms administered Erysipelothrix rhusopathiae and parvovirus vaccination to sows. Vaccination against IAv and PRRSv was carried out on 19 and 21 farms, respectively (of which 11 vaccinated against both). Piglets were vaccinated against porcine circovirus type 2 (PCV-2) on $94.2 \%$ of farms and $75 \%$ also vaccinated against Mhyo. Half of all farms administered prophylactic AM treatments to piglets, typically in the first week of life either after birth or at processing (teeth clipping, iron injection, tail docking, etc. (castration is not routine practice in Irish pig production)). Twenty farms (38.5\% of sample) administered prophylactic treatments to sows mainly via medicated feed or injections around farrowing or weaning. A summary of farm disease status for IAv, PRRSv, Mhyo and APP, and the prevalence of pluck lesions at slaughter, are shown in Table S4. All but one farm was positive for APP. Co-infection with other pathogens was common: $80.7 \%$ of farms $(n=42)$ were positive for at least three of the four pathogens, while $38.4 \%(n=20)$ were positive for all four (see Figure S1). 


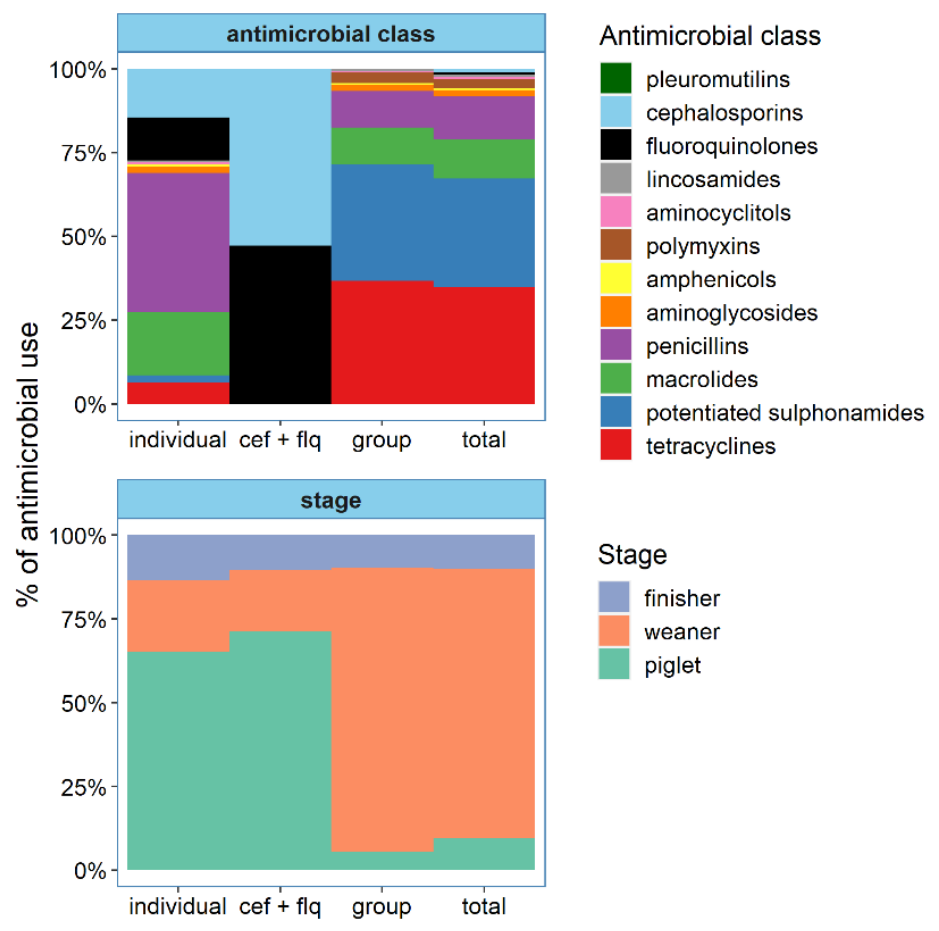

Figure 1. Breakdown of antimicrobial use by antimicrobial class and stage of production for individual treatments, cephalosporin and fluoroquinolone treatments, group oral treatments and total antimicrobial use on 52 Irish farrow-to-finish farms during 2016. Percentage of use refers to the contribution of the antimicrobial class or stage of production to the overall treatment incidence (TI200) indicator. Legend: cef + flq-use of cephalosporins and fluoroquinolones.

The univariable linear regression models for the $\mathrm{TI}_{\text {total }}, \mathrm{TI}_{\text {group }}, \mathrm{TI}_{\text {individual }}$ and $\mathrm{TI}_{\text {ceflq }}$ are summarised in Table S5. The final multivariable models are shown in Table 2. There were significant positive associations between all the pleurisy-related variables $(p \leq 0.05)$ and both $\mathrm{TI}_{\text {total }}$ and $\mathrm{TI}_{\text {group }}$, but these were not retained in the final models. The final multivariable models for $\mathrm{TI}_{\text {total }}$ and $\mathrm{TI}_{\text {group }}$ were similar and explained approximately $53 \%$ and $55 \%$ of the variability, respectively. Farms with higher mortality in the finisher stage and those vaccinating against IAv had higher AMU, while farms home milling and farms with longer weaner stages had lower AMU $(p \leq 0.05)$. There were positive associations between prevalence of lung abscesses and pericarditis and AMU, although these were not significant for the $\mathrm{TI}_{\text {total }}(p \leq 0.1)$. The final multivariable model for $\mathrm{TI}_{\text {individual }}$ explained $29 \%$ of the variability, with the administration of prophylactic AM treatments to piglets, higher biosecurity score in 'vermin and bird control' and prevalence of liver milk spots being positively associated with individual AMU $(p \leq 0.05)$. Farms with better biosecurity scores in 'feed, water and equipment supply' had reduced individual AMU ( $p=0.007)$. Regarding the use of fluoroquinolones and third-generation cephalosporins, the model for $\mathrm{TI}_{\text {ceflq }}$ explained $37 \%$ of the variability. Farms with prophylactic AMU in piglets, those with lower biosecurity scores in 'feed and water supply' and those with higher prevalence of pericarditis used more of these classes $(p \leq 0.05)$. Farms with higher weaner mortality used less $(p=0.002)$, while farms which administered prophylactic AM treatments to sows tended to use more $(p=0.062)$.

The univariable associations between the predictor variables and the use (or not) of the various combinations of antimicrobial class and route of administration (group or individual) are shown in Table S6. The results from the final logistic regression models for AM classes used as group oral treatments are shown in Tables 3 and S7 and are presented as odds ratios with their $95 \%$ confidence intervals. The associations identified in the quantitative analysis of total and group oral AMU were also identified as risk factors 
for use of the most consumed AM classes. Home milling farms were less likely to use tetracyclines $(p=0.048)$ and farms with a longer weaner stage were less likely to use tetracyclines, potentiated sulphonamides or lincosamides as group treatments $(p<0.05)$. Higher finisher mortality was associated with increased odds of potentiated sulphonamide use $(p=0.033)$ and macrolide use $(p=0.014)$. Farms positive for IAv were less likely to use oral penicillins $(p=0.041)$, but those vaccinating against IAv were more likely to use oral tetracyclines, potentiated sulphonamides and macrolides $(p<0.05)$. Higher prevalence of pericarditis was associated with increased odds of penicillin use $(p=0.007)$ and polymyxin use $(p=0.046)$. Farms that administered prophylactic AM treatments to piglets were 10 times more likely to use oral penicillins $(p=0.006)$. Higher scores in the biosecurity categories 'nursery unit management' and 'measures between compartments' were associated with decreased odds of tetracycline use $(p=0.04)$ and polymyxin use $(p=0.026)$, respectively. Higher scores in the 'feed, water and supply of equipment' and 'environment and region' categories tended to reduce the odds of potentiated sulphonamide use $(p<0.1)$.

Table 2. Summary of multivariable linear regression models for total antimicrobial use (AMU) $\left(\mathrm{TI}_{\text {total }}\right)$, group oral AMU ( $\left.\mathrm{TI}_{\text {group }}\right)$, individual $\mathrm{AMU}\left(\mathrm{TI}_{\text {individual }}\right)$ and cephalosporin/fluoroquinolone use $\left(\mathrm{TI}_{\text {ceflq }}\right)$. The outcome variables are expressed as treatment incidence (TI200) and were log-transformed prior to analysis. Both the coefficients on the log scale and the back-transformed estimates are presented.

\begin{tabular}{|c|c|c|c|c|c|}
\hline Outcome Variable & Predictor Variables & Estimate $^{a}$ & Std. Error & $\begin{array}{l}\text { Back-Transformed } \\
\text { Estimate }(95 \% \mathrm{CI})\end{array}$ & $p$ \\
\hline \multirow{7}{*}{$\begin{array}{l}\text { LOG } \mathrm{TI}_{\text {total }} \\
\quad \text { adjusted } \mathrm{R}^{2}=0.53 \\
\quad p<0.001\end{array}$} & Intercept & 3.28 & 0.936 & 26.48 & \\
\hline & Finisher mortality_2016 & 0.28 & 0.135 & $1.32(1.01-1.74)$ & 0.043 \\
\hline & Home milling $($ ref $=$ no $)$ & -1.08 & 0.265 & $0.34(0.2-0.58)$ & 0.000 \\
\hline & Weaner stage (days) & -0.03 & 0.013 & $0.97(0.95-1)$ & 0.027 \\
\hline & IAv vaccination $($ ref $=$ no $)$ & 1.06 & 0.272 & $2.88(1.66-4.97)$ & 0.000 \\
\hline & Lung abscesses (\%) & 0.07 & 0.037 & $1.07(0.99-1.16)$ & 0.070 \\
\hline & Pericarditis (\%) & 0.06 & 0.031 & $1.06(1-1.13)$ & 0.059 \\
\hline \multirow{7}{*}{$\begin{array}{l}\text { LOG } \mathrm{TI}_{\text {group }} \\
\quad \begin{array}{l}\text { adjusted } \mathrm{R}^{2}=0.55 \\
p<0.001\end{array}\end{array}$} & Intercept & 2.93 & 0.832 & 18.72 & \\
\hline & Finisher mortality & 0.28 & 0.120 & $1.33(1.04-1.69)$ & 0.023 \\
\hline & Home milling $($ ref $=$ no $)$ & -0.97 & 0.235 & $0.38(0.23-0.61)$ & 0.000 \\
\hline & Weaner stage (days) & -0.02 & 0.011 & $0.98(0.95-1)$ & 0.041 \\
\hline & IAv vaccination $(\mathrm{ref}=\mathrm{no})$ & 0.95 & 0.242 & $2.58(1.58-4.19)$ & 0.000 \\
\hline & Lung abscesses (\%) & 0.07 & 0.033 & $1.07(1-1.14)$ & 0.046 \\
\hline & Pericarditis (\%) & 0.06 & 0.028 & $1.06(1-1.12)$ & 0.037 \\
\hline \multirow{5}{*}{$\begin{array}{l}\text { LOG } \mathrm{TI}_{\text {individual }} \\
\qquad \begin{array}{l}\text { adjusted } \mathrm{R}^{2}=0.29 \\
\quad p<0.001\end{array}\end{array}$} & Intercept & -0.58 & 0.473 & 0.56 & \\
\hline & $\begin{array}{c}\text { Feed, water and equipment } \\
\text { supply b }\end{array}$ & -0.01 & 0.007 & $0.99(0.97-1)$ & 0.048 \\
\hline & Vermin and bird control $^{\mathrm{b}}$ & 0.01 & 0.005 & $1.01(1-1.02)$ & 0.018 \\
\hline & Piglet prophylaxis $(\mathrm{ref}=\mathrm{no})^{\mathrm{c}}$ & 0.60 & 0.192 & $1.82(1.23-2.67)$ & 0.003 \\
\hline & Liver milk spots $(\%)$ & 0.01 & 0.004 & $1.01(1-1.02)$ & 0.018 \\
\hline \multirow{6}{*}{$\begin{array}{l}\text { LOG } \mathrm{TI}_{\text {ceflq }} \\
\quad \text { adjusted } \mathrm{R}^{2}=0.37 \\
\quad p<0.001\end{array}$} & Intercept & -1.32 & 0.816 & 0.27 & \\
\hline & Weaner mortality & -0.41 & 0.126 & $0.66(0.51-0.85)$ & 0.002 \\
\hline & $\begin{array}{c}\text { Feed, water and equipment } \\
\text { supply b }\end{array}$ & -0.03 & 0.012 & $0.97(0.95-1)$ & 0.031 \\
\hline & Sow prophylaxis $(\mathrm{ref}=\mathrm{no})^{\mathrm{C}}$ & 0.72 & 0.378 & $2.06(0.96-4.41)$ & \\
\hline & Piglet prophylaxis $(\mathrm{ref}=\mathrm{no})^{\mathrm{C}}$ & 1.16 & 0.350 & $3.19(1.58-6.45)$ & 0.002 \\
\hline & Pericarditis $(\%)$ & 0.14 & 0.041 & $1.15(1.06-1.25)$ & 0.001 \\
\hline
\end{tabular}

Constants were added to the $\mathrm{TI}_{\text {individual }}$ and $\mathrm{TI}_{\text {ceflq }}$ ( 1 and 0.01 , respectively) before log transformation. The back-transformed estimates refer to the multiplicative effect per unit change of predictor variable. For example, farms vaccinating against IAv had 2.88 times higher treatment incidence than farms not vaccinating. ${ }^{\mathrm{a}}$ Log scale. ${ }^{\mathrm{b}}$ Biocheck.Ugent ${ }^{\mathrm{TM}}$ biosecurity score. ${ }^{\mathrm{c}}$ Prophylactic antimicrobial use. Legend: CI—confidence interval; TI—-treatment incidence; IAv—influenza A virus. 


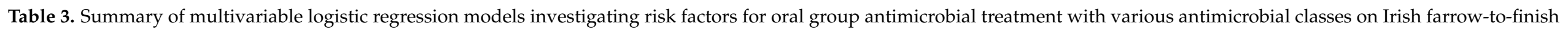
pig farms $(n=52)$ during 2016. Predictor variables with $p \leq 0.1$ were retained in the final models. Results are presented as odds ratios with $95 \%$ confidence intervals.

\begin{tabular}{|c|c|c|c|c|c|c|c|c|}
\hline & \multicolumn{8}{|c|}{ Outcome Variables: Oral Group Treatment with Antimicrobial Class } \\
\hline & Tetracyclines & $\begin{array}{c}\text { Potentiated } \\
\text { Sulphonamides }\end{array}$ & Penicillins & Macrolides & Lincosamides & Amphenicols & Aminoglycosides & Polymyxins \\
\hline Predictor Variable & OR $(95 \% \mathrm{CI})$ & OR $(95 \% \mathrm{CI})$ & OR $(95 \% \mathrm{CI})$ & OR $(95 \%$ CI $)$ & OR $(95 \% \mathrm{CI})$ & OR $(95 \%$ CI $)$ & OR $(95 \%$ CI $)$ & OR $(95 \% \mathrm{CI})$ \\
\hline Herd characteristics & & & & & & & & \\
\hline Home milling $(\mathrm{ref}=\mathrm{no})$ & $0.16(0.02-0.86)$ & - & - & - & - & - & - & - \\
\hline Finisher mortality $(\%)$ & - & $7.7(1.7-88.88)$ & - & $2.81(1.32-7.18)$ & - & - & - & - \\
\hline Age at weaning (days) & - & - & - & $1.32(1.05-1.78)$ & - & - & - & - \\
\hline Weaner stage (days) & $0.89(0.78-0.98)$ & $0.69(0.45-0.87)$ & - & - & $0.9(0.8-0.98)$ & - & - & - \\
\hline Finisher stage (days) & - & - & - & - & - & - & $1.07(1-1.16)$ & - \\
\hline No. of sows per employee & - & - & - & - & - & - & $0.98(0.95-1.00)$ & $1.02(1-1.04)$ \\
\hline Farmer experience (years) & - & - & - & - & - & - & $1.08(1.00-1.18)$ & - \\
\hline Youngest building (years) & - & - & - & - & $1.3(1.07-1.68)$ & - & - & - \\
\hline Biosecurity scores & & & & & & & & \\
\hline $\begin{array}{l}\text { Feed, water and equipment } \\
\text { supply }\end{array}$ & - & $0.92(0.82-1.00)$ & - & - & - & - & - & - \\
\hline Environment and region & - & $0.95(0.87-1.00)$ & - & - & - & - & - & - \\
\hline Nursery unit management & $0.93(0.87-0.99)$ & - & - & - & - & - & - & - \\
\hline $\begin{array}{l}\text { Measures between compartments } \\
\text { and use of equipment } \\
\text { Pluck lesions at slaughter and } \\
\text { disease status }\end{array}$ & - & - & - & - & - & - & - & $0.94(0.89-0.99)$ \\
\hline Pleurisy (\%) & - & $1.11(1.03-1.25)$ & - & - & - & - & - & - \\
\hline Moderate/severe pleurisy (\%) & - & - & - & - & - & - & $0.89(0.81-0.96)$ & - \\
\hline Scars $(\%)$ & $1.13(1.02-1.3)$ & - & - & - & - & - & $1.1(1.02-1.23)$ & - \\
\hline Lung abscesses (\%) & - & - & - & - & - & $1.47(1.09-2.9)$ & - & - \\
\hline Pericarditis (\%) & - & - & $1.35(1.11-1.73)$ & - & - & - & - & $1.19(1.01-1.44)$ \\
\hline Liver milk spots (\%) & - & - & - & - & - & $1.04(1-1.11)$ & - & - \\
\hline IAv status (ref = negative) & - & - & $0.11(0.01-0.74)$ & - & - & - & - & - \\
\hline Mhyo status (ref = negative) & - & - & (1) & - & $\begin{array}{c}134.31 \\
(4.66->9999)\end{array}$ & - & - & - \\
\hline PRRSv status (ref $=$ negative) & - & - & - & - & 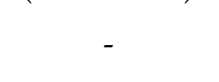 & $\begin{array}{c}270.67 \\
(5.26->9999)\end{array}$ & - & - \\
\hline
\end{tabular}


Table 3. Cont

Outcome Variables: Oral Group Treatment with Antimicrobial Class

\begin{tabular}{|c|c|c|c|c|c|c|c|c|}
\hline & Tetracyclines & $\begin{array}{c}\text { Potentiated } \\
\text { Sulphonamides }\end{array}$ & Penicillins & Macrolides & Lincosamides & Amphenicols & Aminoglycosides & Polymyxins \\
\hline \multicolumn{9}{|l|}{$\begin{array}{l}\text { Vaccination and prophylactic } \\
\text { antimicrobial use practices }\end{array}$} \\
\hline $\mathrm{IAv}$ vaccination $(\mathrm{ref}=\mathrm{no})$ & $\begin{array}{c}12.53 \\
(1.72-183.73)\end{array}$ & $\begin{array}{c}106.48 \\
(5.14->9999)\end{array}$ & - & $\begin{array}{c}24.11 \\
(4.8-191.38)\end{array}$ & - & - & - & - \\
\hline Piglet prophylaxis $(\mathrm{ref}=\mathrm{no})$ & (19 & - & $\begin{array}{c}10.18 \\
(2.22-64.81)\end{array}$ & (120 & - & $\begin{array}{c}11.3 \\
(1.09-367.08)\end{array}$ & - & - \\
\hline
\end{tabular}

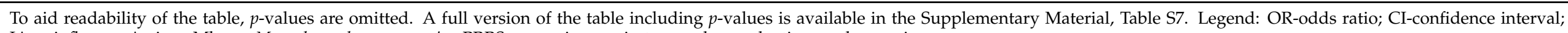
IAv—influenza A virus; Mhyo-Mycoplasma hyopneumoniae; PRRSv—-porcine respiratory and reproductive syndrome virus. 
The results from the final logistic regression models for AM classes used as individual treatments are summarised in Table 4 and Supplementary Table S8. All farms used injectable penicillins ( $41.7 \%$ of all individual treatments), and thus this class was excluded from the analysis. There was a tendency for increased odds of injectable tetracycline use on farms with higher weaner mortality $(p=0.072)$. Farms with higher piglet or finisher mortality tended to be less likely to use injectable macrolides $(p<0.1)$. The number of sows per employee was positively associated with the use of injectable aminoglycosides and third-generation cephalosporins $(p<0.05)$. Higher scores in the biosecurity categories 'disease management' and 'feed, water and supply of equipment' were associated with decreased odds of tetracycline use $(p=0.08)$ and fluoroquinolone use $(p=0.028)$, respectively. However, a number of biosecurity categories were associated with increased odds of use for certain AM classes. Farms with higher prevalence of liver milk spot lesions were less likely to use tetracyclines $(p=0.021)$ but more likely to use lincosamides $(p=0.017)$. In agreement with the findings for the $\mathrm{TI}_{\text {ceflq }}$ model, farms that administered prophylactic AM treatments to piglets were 4 times more likely to use third-generation cephalosporins $(p=0.074)$, and those that administered prophylactic AMs to sows were 17 times more likely to use fluoroquinolones $(p=0.088)$. 


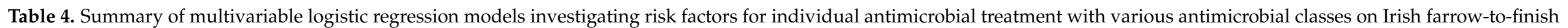
pig farms $(n=52)$ during 2016. Results are presented as odds ratios with $95 \%$ confidence intervals.

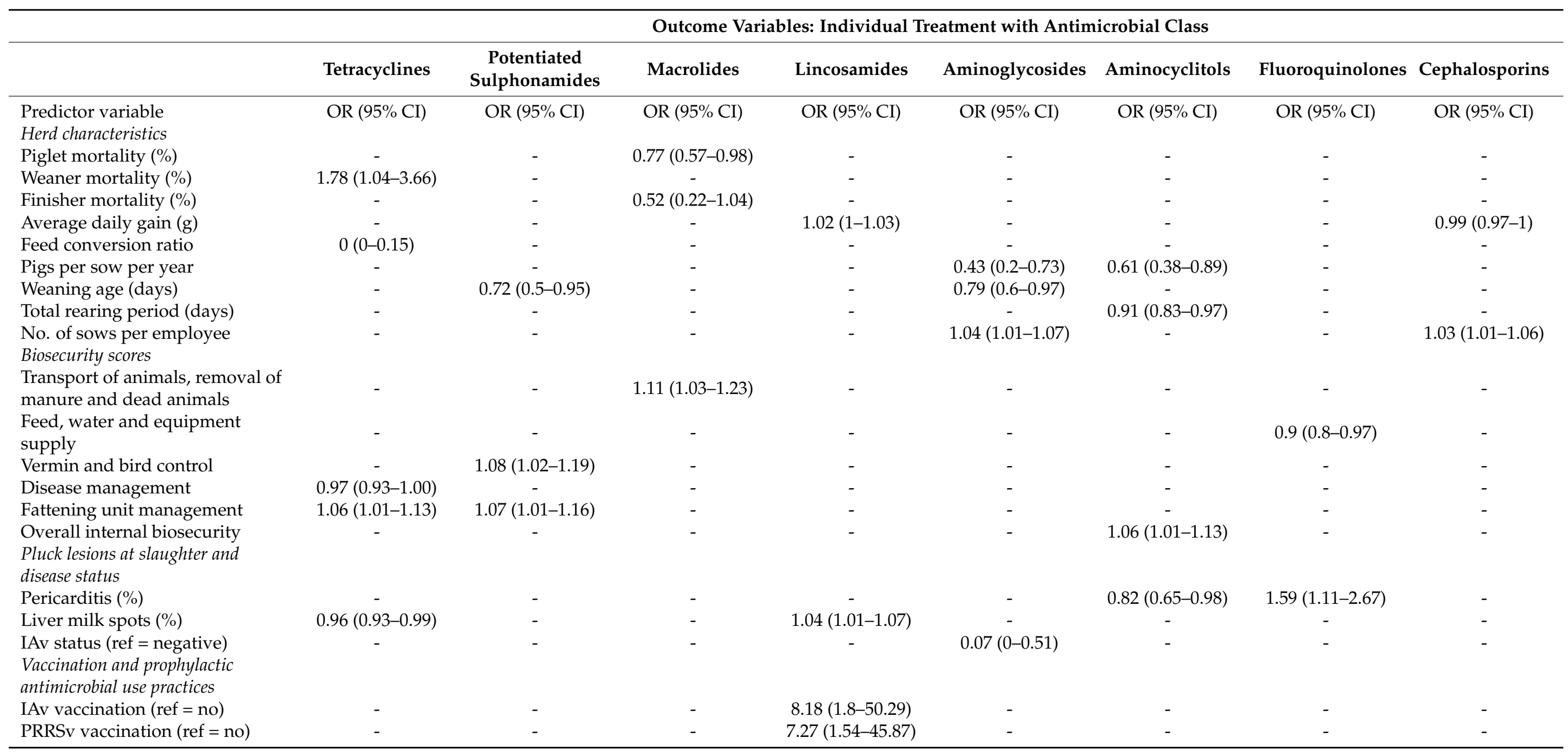


Table 4. Cont.

Outcome Variables: Individual Treatment with Antimicrobial Class

\begin{tabular}{|c|c|c|c|c|c|c|c|c|}
\hline & Tetracyclines & $\begin{array}{c}\text { Potentiated } \\
\text { Sulphonamides }\end{array}$ & Macrolides & Lincosamides & Aminoglycosides & Aminocyclitols & Fluoroquinolones & Cephalosporins \\
\hline Piglet prophylaxis $(\mathrm{ref}=\mathrm{no})$ & - & $0.01(0-0.21)$ & - & - & - & - & - & $4.35(0.96-26.2)$ \\
\hline Sow prophylaxis $(\mathrm{ref}=\mathrm{no})$ & - & - & - & - & - & - & $\begin{array}{c}17.22 \\
(1.15-1032.14)\end{array}$ & - \\
\hline
\end{tabular}

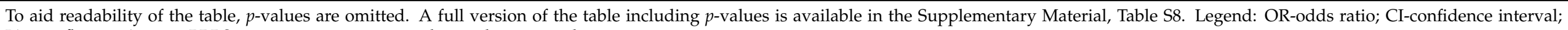
IAv—influenza A virus; PRRSv—-porcine respiratory and reproductive syndrome virus. 


\section{Discussion}

This study explored the risk factors for AMU on Irish pig farms using data collected during previously published studies investigating AMU, biosecurity and respiratory disease on Irish pig farms $[47,52,53]$. The study farms were clients of the Teagasc advisory service and participated on a voluntary basis. This may have introduced selection bias, where farms with a prior interest in improving herd health were more likely to enrol, and therefore it cannot be assumed that the study sample is representative of the entire industry. Nevertheless, it represented approximately $29 \%$ of the national herd, and the findings of this investigation provide useful insights into the drivers for AMU in the commercial pig sector in Ireland. The linear regression models identified the main risk factors for the amounts of AMs used overall and for the primary modes of administration (group oral and individual), as well as for the fluoroquinolone and third-generation cephalosporin classes. The latter category is of interest due to the importance of these classes to public health and concerns over resistance $[63,64]$, as well as the fact that, although volumes are relatively low, use is observed on most Irish farms [47]. The models for all AMU $\left(\mathrm{TI}_{\text {total }}\right)$ and oral group treatments $\left(\mathrm{TI}_{\text {group }}\right)$ provided similar results because the majority of treatments are administered orally, particularly via medicated feed. Individual AMU and cephalosporin/fluoroquinolone use also had risk factors in common, which is unsurprising since cephalosporins (injectable) and fluoroquinolones (injectable or oral dose) are relatively common individual treatments. The logistic regression models identified a number of risk factors for the use of certain combinations of administration route and class of AM. It should be noted that these models did not distinguish between low or high use, for example, the absence of use of a particular AM does not imply less AMU overall as another class may be used in its stead. For ease of interpretation, the results are discussed below in terms of the broad categories of risk factors.

\subsection{Farm Characteristics}

Farms home milling at least one of their diets had approximately $66 \%$ lower AMU than those that purchased all their feed. In particular, they were less likely to use group tetracycline treatment $(p=0.048)$, which was the most widely and heavily used oral treatment. This may relate to structural differences in AM delivery as home milling farms are not permitted to manufacture medicated feed unless they also possess a licence to do so [65]. Therefore, while home milling farms still have access to AMs, the "ease" of access differs between both groups, and this may point to a social factor whereby convenience and habit could explain some of the routine prophylactic AMU in medicated feed practised on the study farms. On the other hand, home milling may confer health benefits as they are reported to have lower finisher mortality compared to those purchasing their feed [66]. The reasons for this are not clear but could relate to the diet form, for example, lower prevalence of Brachyspira piloscoli was reported for Danish farms that provided home-milled or nonpelleted feed [67].

Older weaning age has been associated with lower AMU on European farms [17,24], likely because older piglets are less susceptible to the associated stresses of moving, mixing and diet change $[68,69]$. In this study, farms with a later weaning age were more likely to use macrolide group treatments $(p=0.037)$, but weaning age was not associated with the quantity of AMU. The reason for the association with macrolide use is not obvious, but the lack of association with quantitative AMU is likely due to insufficient variability between farms as most of them weaned pigs at 29 days. After weaning, the weaner stage on Irish farms is typically split into two sections, roughly $4-5$ weeks each, with different housing and feeding infrastructure. Medicating throughout both phases was common on the studied farms. Contrary to the authors' belief that a longer weaner phase might be associated with increased AMU, farms with a longer stay in the weaner stage had lower AMU. These farms were less likely to use oral tetracyclines or potentiated sulphonamides, the classes that contributed most to overall use, and they were also less likely to use oral 
lincosamides. The contrary results could relate to differences in accommodation associated with a longer weaning phase.

Farms with a higher number of sows per employee were more likely to use polymyxins (colistin) $(p=0.072)$ and cephalosporins (ceftiofur) $(p=0.029)$. Conversely, such farms were less likely to use oral aminoglycosides (apramycin) $(p=0.035)$. Colistin and apramycin are primarily indicated for gastrointestinal disease [14], and the conflicting results here may relate to the choice of one over the other on these farms when treating gastrointestinal disease. Colistin and ceftiofur are both HP CIAs, and the observation that less well-staffed farms are more likely to use them warrants closer inspection. These farms may have more health problems due to a lack of staff and thus may be more inclined to use so-called 'last resort' drugs. Convenience may be a factor too as the most widely used formulation of ceftiofur is long-acting, although this association was not observed for other long-acting parenteral AMs (e.g., macrolides).

\subsection{Farm Performance Indicators}

Finisher mortality is impacted by a variety of factors, including management, environment and infectious disease [70,71], and in this study, each additional $1 \%$ increase in mortality was associated with $33 \%$ higher AMU. This association has been previously demonstrated for the use of in-feed medication in Spain and the UK [26,72] and for AMU on heavy pig-fattening farms in Italy [73]. Farms with higher finisher mortality were also more likely to use oral potentiated sulphonamides or macrolides. Given that tetracyclines were the most applied group treatments, this might indicate a greater likelihood to deviate from the 'standard' use of tetracyclines. Since finishers accounted for just $10 \%$ of total AMU, finisher mortality may also reflect overall health through all stages of production. In this study, all farms that used medicated feed in finisher pigs also provided medicated diets in the weaner stage, suggesting that these farms may also have health problems in the earlier stages. Higher weaner mortality was associated with lower use of fluoroquinolones and cephalosporins $\left(\mathrm{TI}_{\text {ceflq }}\right)$. It might be expected that weaner mortality would increase the use of these drugs, but farms with higher weaner mortality due to infectious disease may be more likely to focus on group treatments and, in this study, tended to have higher odds of parenteral tetracycline use $(p=0.072)$.

\subsection{Biosecurity Practices}

In contrast to other European studies, there was no association between the internal, external or overall biosecurity scores and total AMU [24,25]. Irish farms generally had high external biosecurity scores, mainly because most farms are closed herds, neither buying replacement gilts or finisher pigs from other sources. This may partly explain the lack of association with AMU. However, farms with better scores in the biosecurity category of 'feed, water and equipment supply' had lower use of individual treatments including cephalosporins and fluoroquinolones, and they were also less likely to use oral potentiated sulphonamides. Feed and water as well as their associated delivery and storage are potential sources of pathogens [74]. There were other associations between certain biosecurity categories and patterns of use. Better scores in the biosecurity category 'measures between compartments' were associated with lower odds of using polymyxins, which may link poor biosecurity with gastrointestinal disease. Although biosecurity scores were not associated with overall AMU in this study, there is evidence that farms which improve their biosecurity can reduce their AMU $[75,76]$. The generally lower internal biosecurity scores on Irish farms [52] demonstrate an opportunity for improvement, and the PigHealthCheck initiative run by Animal Health Ireland, which provides for free biosecurity assessments, is helping to raise awareness on this topic (https:/ / animalhealthir eland.ie/programmes/pig-healthcheck/introduction/ last accessed 20 September 2021). 


\subsection{Respiratory Disease}

Respiratory disease is an important cause of mortality in pig production [77] and a major indication for AMU. In this study, neither farm status for IAv, PRRSv, Mhyo or APP, nor the prevalence of pneumonia or pleurisy were directly associated with total or group AMU. Instead, pericarditis and lung abscesses were positively associated with AMU, which increased by $7 \%$ and $6 \%$ respectively, for each percentage increase in farm prevalence. Pericarditis was also associated with higher fluoroquinolone use (approximately $15 \%)$ and higher odds of oral penicillin use $(p=0.007)$. Fluoroquinolones and penicillins are both are indicated for the treatment of APP infection and the latter is often used to treat and control Streptococcus suis infection [14]. Lung abscesses and pericarditis may be extensions of pneumonia and/or pleurisy involving infection with APP, Pasteurella multocida or Streptococcus suis [78], or they may be sequelae of systemic infections such as S. suis or Glaesserella parasuis. Thus, these lesions may be indicators of general health on the farm as S. suis and G. parasuis are also implicated in meningitis, polyserositis and arthritis, which are common conditions in pigs post-weaning [79,80]. Higher individual AMU associated with increased prevalence of liver milk spots at slaughter may be a direct result of Ascaris suum infestation, or it may indicate deficiencies in farm hygiene. Ascaris suum infestation has also been shown to interfere with Mhyo vaccination [81], further highlighting the importance of parasite control on pig farms.

\subsection{Disease Management}

Farms that administered prophylactic AM treatments to piglets had approximately $82 \%$ higher individual $\mathrm{AMU}$ ( $\left.\mathrm{TI}_{\text {individual }}\right)$, higher use of cephalosporins and/or fluoroquinolones $\left(\mathrm{TI}_{\text {ceflq }}\right)$ and they were also 10 times more likely to use oral penicillins $(p=0.006)$. Prophylactic AMU in piglets was observed on $50 \%$ of the study farms and is also common in other countries $[82,83]$. It usually occurs in the first week of life alongside procedures such as teeth clipping, tail docking and iron injection. The purpose of these treatments is to prevent infections associated with these procedures or with neonatal diseases endemic to the farm (e.g., meningitis or colibacillosis). Amoxicillin injection was the most common treatment used, but ceftiofur, enrofloxacin and long-acting macrolides were also used. The association with oral penicillin use might indicate farms using both strategies to control S. suis infection. Whether these treatments reduce morbidity and mortality on these farms is unknown; however, this finding shows that the practice does not reduce AMU. Farms that administered prophylactic treatments to sows tended to use more fluoroquinolones in growing pigs. This may reflect the disease status on certain farms or perhaps a behavioural pattern, where injudicious AMU practices co-occur on some farms (or it may reflect the corollary: good antimicrobial stewardship on some farms neither practising prophylaxis nor using HP CIAs). Farms vaccinating against IAv had 2.9 times higher $\mathrm{TI}_{\text {total }}$ compared to non-vaccinating farms. A similar association was observed in French herds in the pan-European study carried out by Collineau et al., who also reported other positive associations between vaccination and AMU for a number of country/pathogen combinations [17]. In Denmark, a retrospective study investigating trends in AMU and vaccination between 2007 and 2013 found no link between increased vaccination and reduction in AMU that occurred during this period [84], while others found that vaccination was associated with higher AMU [34,35]. This may seem counterintuitive, but the authors of these studies suggest that farmers may use vaccinations to control diseases that are already on the farm in conjunction with AMs, while conversely, farms free from a given disease do not need to vaccinate and may not need AMs. In the present study, higher AMU on farms vaccinating against IAv may be a consequence of more severe respiratory disease. An association between influenza and pleurisy was reported for the larger cohort of Irish farms [53] and by others [85]. Co-infection is a common feature of the Porcine Respiratory Disease Complex (PRDC), and often, these co-infections are synergistic [86]. It is noteworthy that 11 of the 19 farms vaccinating against IAv also vaccinated against PRRSv. This is an interesting observation given that Calderon Diaz et al. found 
that Irish farms vaccinating against IAv or PRRSv are less profitable than farms that were positive but not vaccinating [87]. This could suggest that farms with high AMU are also less profitable, but further research is required. These findings highlight that vaccination alone may not be enough to eliminate disease and reduce AMU. However, their proven efficacy against a range of porcine infectious diseases [31-33] means that they are a key tool in this regard [28].

\subsection{Implications for Irish Pig Sector}

Prophylaxis was one of the main drivers of AMU in this study. This was seen in the relationship between AMU and home milling and in the influence that prophylactic practices in sows and piglets had on the use of oral penicillins and HP CIAs. European Union regulations from 2022 mean that prophylactic AMU in animals will be banned in almost all circumstances, and metaphylactic treatments (group treatments in the presence of disease) and the use of certain AMs, likely the EMA category B drugs [64], will only be allowed where clearly justified [88]. This will require significant changes in management practices on Irish farms as well as veterinary prescribing practices. One feature of prophylactic use is that it may happen whether disease is present or not. This presents an opportunity in that unnecessary use is easier to eliminate and sizeable reductions have been achieved in some countries with similar patterns of AMU, such as the United Kingdom, in recent years [89]. Reducing the need for AMU is more challenging, however, requiring improvements in overall herd health. Irish farmers previously identified economic concerns over international competition and cost effectiveness of alternatives to AMU as barriers to reducing in-feed medication [40], and there were similar findings amongst British farmers, where high investment costs and staffing difficulties were cited as barriers [30]. Nevertheless, this challenge has been met in other countries $[90,91]$ and can be achieved without impacting performance or profit [92-94]. One challenge facing farmers is the forthcoming ban on the use of zinc oxide in the EU from 2022 [95]. In common with other countries such as Denmark [96], zinc oxide is widely used to control gastroenteritis on Irish farms: all but one of the study farms used it in at least one diet in 2016 (data not shown). Data on the prevalence of porcine gastrointestinal disease in Ireland are lacking and none were available for use in this study. Therefore, it is unknown how gastrointestinal disease influences AMU on Irish pig farms and future research would be of benefit. This study shows where some improvements could be made to help farms reduce AMU. Further research is needed to explore if farms practising home milling have advantages in management or nutrition that can be applied to other farms. Farms should ensure they have adequate parasite control regimens in place. High farm prevalence of pericarditis warrants a detailed investigation since there are multiple aetiologies, and indeed this is a poorly researched topic. The structure of the Irish pig industry presents some advantages in terms of AMU, many of which have not been utilised. Firstly, the sector is relatively small-there are approximately 300 commercial pig farms in Ireland. This means that potential targeted interventions to aid a reduction in AMU, for example farms with high prevalence of pericarditis, would involve a small number of farms. Secondly, almost all herds are closed, meaning that neither gilts nor fattening pigs are purchased from other farms. These practices (i.e., purchase of animals) have been associated with increased respiratory disease [97] and mortality [98]. While AMU and respiratory disease are not lower in Ireland at present, the structure of the industry may make it easier to sustain any improvements it can make.

\section{Conclusions}

This study identified prophylactic use and respiratory disease as the main drivers for antimicrobial use in Irish pig production. Farms that milled their own feed had lower AMU, while farms with higher prevalence of pericarditis, lung abscesses and liver milk spot lesions, as well as with higher finisher mortality, and those vaccinating for IAv had higher AMU. Farms that administered prophylactic AM treatments to sows or piglets had higher use of HP CIAs. These findings highlight areas of farm management where 
interventions may aid in reducing AMU on Irish pig farms, although further investigations at the individual farm level and in the wider population are required.

Supplementary Materials: The following are available online at https://www.mdpi.com/article/1 0.3390/ani11102828/s1, Figure S1: Venn diagram summarising co-infection with four respiratory pathogens on 52 Irish farrow-to-finish pig farms. Table S1: Summary of farm characteristics and performance for 52 Irish farrow-to-finish pig farms from 2016. Table S2: Summary of biosecurity scores evaluated using the Biocheck.UGent ${ }^{\mathrm{TM}}$ questionnaire from 52 Irish farrow-to-finish pig farms in 2016. Table S3: Summary of prevalence of pluck lesions and disease status on 52 Irish farrow-to-finish pig farms. Table S4: Summary of vaccination and prophylactic antimicrobial use practices on 52 Irish farrow-to-finish pig farms during 2016. Table S5: Summary of $p$-values for the univariable linear regression models investigating risk factors for antimicrobial use (AMU) on 52 Irish farrow-to-finish pig farms during 2016. Table S6: Summary of univariable associations between a range of risk factors and the use of various antimicrobial classes via oral group or individual modes of treatment on 52 Irish farrow-to-finish pig farms during 2016. Table S7: Summary of multivariable logistic regression models investigating risk factors for oral group antimicrobial treatment with various antimicrobial classes on Irish farrow-to-finish pig farms $(n=52)$ during 2016 (this is a companion to Table 3). Table S8: Summary of multivariable logistic regression models investigating risk factors for oral group antimicrobial treatment with various antimicrobial classes on Irish farrow-to-finish pig farms $(n=52)$ during 2016 (this is a companion to Table 4).

Author Contributions: L.O. drafted the manuscript and performed the data analysis and data visualisation; L.O., M.R.d.C., J.A.C.D. and E.G.M. performed the data collection in the field; M.R.d.C. carried out the pluck lesion evaluation and collection of blood samples; L.O., J.A.C.D., S.O. and E.G.M. designed the study; L.O., J.A.C.D. and E.G.M. performed the statistical analysis; E.G.M. and F.C.L. were responsible for the conceptualisation and design of, and funding acquisition for, the cross-sectional studies on which this investigation is based; L.O., M.R.d.C., J.A.C.D., F.C.L. and E.G.M. reviewed and edited the manuscript. All authors have read and agreed to the published version of the manuscript.

Funding: This study was conducted within the AMURAP project (Antimicrobial Use and Resistance in Animal Production) which investigates AMU and AMR in the Irish pig and poultry industries. This project is funded by the Irish Department of Agriculture Food and the Marine (grant reference number $15 \mathrm{~S} 676)$. The studies investigating biosecurity and respiratory disease were funded by the Irish Department of Agriculture, Food and the Marine under the Research Stimulus Fund (PathSurvPig 14 $\mathrm{S}$ 832). The funders had no role in the study design, data collection and analysis, decision to publish, or preparation of the manuscript.

Institutional Review Board Statement: The participating farmers gave informed written consent for the use of their data in this study on condition of anonymity. This research did not involve the use of animal subjects. Thus, formal approval by an ethics committee was not required under Irish regulations.

Informed Consent Statement: The participating farmers gave informed written consent for the use of their data in this study on condition of anonymity.

Data Availability Statement: The datasets used and/or analysed during the current study are available from the corresponding author upon reasonable request.

Acknowledgments: The authors would like to thank the participating farmers, their private veterinary practitioners and the staff at participating slaughterhouses for their cooperation with this study. The authors would also like to thank the pig development officers in the Teagasc Pig Development Department for their advice and assistance with farm recruitment, farm visits and data collection. James Gibbons is acknowledged for his role in funding acquisition for the AMURAP project and its initiation. Finally, we would like to thank Rose Fitzgerald from the Munster Technological University for assisting with the serological testing.

Conflicts of Interest: The authors declare no conflict of interest. The funders had no role in the design, execution, interpretation, or writing of the study. 


\section{References}

1. World Health Organisation. Global Action Plan on Antimicrobial Resistance. 2015. Available online: https://apps.who.int/iris/ bitstream/handle/10665/193736/9789241509763_eng.pdf?sequence=1 (accessed on 2 April 2021).

2. Department of Health. Ireland's National Action Plan on Antimicrobial Resistance 2017-2020. (iNAP). 2017. Available online: https:/ / www.agriculture.gov.ie/media/migration/animalhealthwelfare/amr/inap/IrelandNationalActionPlanAntimic robialResistance030818.pdf (accessed on 2 December 2020).

3. European Commission. A European One Health Action Plan against Antimicrobial Resistance (AMR). 2017. Available online: https:/ / ec.europa.eu/health/amr/sites/health/files/antimicrobial_resistance/docs/amr_2017_action-plan.pdf (accessed on 2 April 2021).

4. Tiseo, K.; Huber, L.; Gilbert, M.; Robinson, T.P.; van Boeckel, T.P. Global Trends in Antimicrobial Use in Food Animals from 2017 to 2030. Antibiotics 2020, 9, 918. [CrossRef]

5. Aarestrup, F.M. The Livestock Reservoir for Antimicrobial Resistance: A Personal View on Changing Patterns of Risks, Effects of Interventions and the Way Forward. Phil. Trans. R. Soc. B 2015, 370, 20140085. [CrossRef]

6. Tang, K.L.; Caffrey, N.P.; Nóbrega, D.B.; Cork, S.C.; Ronksley, P.E.; Barkema, H.W.; Polachek, A.J.; Ganshorn, H.; Sharma, N.; Kellner, J.D.; et al. Restricting the Use of Antibiotics in Food-Producing Animals and Its Associations with Antibiotic Resistance in Food-Producing Animals and Human Beings: A Systematic Review and Meta-Analysis. Lancet Planet. Health 2017, 1, e316-e327. [CrossRef]

7. DANMAP (Danish Integrated Antimicrobial Resistance Monitoring and Research Programme). DANMAP 2019-Use of Antimicrobial Agents and Occurrence of Antimicrobial Resistance in Bacteria From Food Animals, Food and Humans in Denmark. 2020. Available online: https:/ / www.danmap.org/reports/2019 (accessed on 23 January 2021).

8. The Netherlands Veterinary Medicines Institute. Usage of Antibiotics in Agricultural Livestock in The Netherlands in 2018. Trends and Benchmarking of Livestock Farms and Veterinarians. 2020. Available online: https://cdn.i-pulse.nl/autoriteitdiergeneesmid delen/userfiles/EN/SDa-rapporten/sda-rapport-usage-of-antibiotics-in-agricultural-livestock-in-2019-corr-fig5b.(1).pdf (accessed on 23 January 2021).

9. Belvet-SAC. Belgian Veterinary Surveillance of Antibacterial Consumption National Consumption Report 2019. 2020. Available online: https:/ / belvetsac.ugent.be/BelvetSac_report_2019.pdf (accessed on 23 January 2021).

10. Sjölund, M.; Postma, M.; Collineau, L.; Lösken, S.; Backhans, A.; Belloc, C.; Emanuelson, U.; Beilage, E.G.; Stärk, K.; Dewulf, J. Quantitative and Qualitative Antimicrobial Usage Patterns in Farrow-to-Finish Pig Herds in Belgium, France, Germany and Sweden. Prev. Vet. Med. 2016, 130, 41-50. [CrossRef] [PubMed]

11. Sarrazin, S.; Joosten, P.; Gompel, L.V.; Luiken, R.E.C.E.; Mevius, D.J.; Wagenaar, J.A.; Heederik, D.J.J.J.; Dewulf, J. Quantitative and Qualitative Analysis of Antimicrobial Usage Patterns in 180 Selected Farrow-to-Finish Pig Farms from Nine European Countries Based on Single Batch and Purchase Data. J. Antimicrob. Chemother. 2019, 74, 807-816. [CrossRef] [PubMed]

12. Schwarz, S.; Kehrenberg, C.; Walsh, T.R. Use of Antimicrobial Agents in Veterinary Medicine and Food Animal Production. Int. J. Antimicrob. Agents 2001, 17, 431-437. [CrossRef]

13. Prescott, J.F. Antimicrobial Use in Food and Companion Animals. Anim. Health Res. Rev. 2008, 9, 127-133. [CrossRef] [PubMed]

14. Burch, D.G. Antimicrobial drug use in swine. In Antimicrobial Therapy in Veterinary Medicine; Giguère, S., Prescott, J.F., Dowling, P.M., Eds.; John Wiley and Sons, Inc.: Hoboken, NJ, USA, 2013; pp. 553-568. ISBN 9780470963029.

15. Jensen, V.; Eorg, H.; Aarestrup, F. Indications and Patterns of Therapeutic Use of Antimicrobial Agents in the Danish Pig Production from 2002 to 2008. J. Vet. Pharmacol. Ther. 2012, 35, 33-46. [CrossRef]

16. Van Rennings, L.; von Münchhausen, C.; Ottilie, H.; Hartmann, M.; Merle, R.; Honscha, W.; Käsbohrer, A.; Kreienbrock, L. Cross-Sectional Study on Antibiotic Usage in Pigs in Germany. PLoS ONE 2015, 10, e0119114. [CrossRef]

17. Collineau, L.; Bougeard, S.; Backhans, A.; Dewulf, J.; Emanuelson, U.; Beilage, G.E.; Lehébel, A.; Lösken, S.; Postma, M.; Sjölund, M.; et al. Application of Multiblock Modelling to Identify Key Drivers for Antimicrobial Use in Pig Production in Four European Countries. Epidemiol. Infect. 2018, 146, 1003-1014. [CrossRef]

18. Kruse, A.; Kristensen, C.; Lavlund, U.; Stege, H. Antimicrobial Prescription Data in Danish National Database Validated against Treatment Records in Organic Pig Farms and Analysed for Associations with Lesions Found at Slaughter. BMC Vet. Res. 2019, 15, 218. [CrossRef]

19. Vieira, A.R.; Pires, S.M.; Houe, H.; Emborg, H.-D. Trends in Slaughter Pig Production and Antimicrobial Consumption in Danish Slaughter Pig Herds, 2002-2008. Epidemiol. Infect. 2010, 139, 1601-1609. [CrossRef] [PubMed]

20. Van der Fels-Klerx, H.; Puister-Jansen, L.; van Asselt, E.; Burgers, S. Farm Factors Associated with the Use of Antibiotics in Pig Production. J. Anim. Sci. 2011, 89, 1922-1929. [CrossRef]

21. Hemme, M.; Ruddat, I.; Hartmann, M.; Werner, N.; van Rennings, L.; Käsbohrer, A.; Kreienbrock, L. Antibiotic Use on German Pig Farms-A Longitudinal Analysis for 2011, 2013 and 2014. PLoS ONE 2018, 13, e0199592. [CrossRef] [PubMed]

22. Arnold, C.; Schüpbach-Regula, G.; Hirsiger, P.; Malik, J.; Scheer, P.; Sidler, X.; Spring, P.; Peter-Egli, J.; Harisberger, M. Risk Factors for Oral Antimicrobial Consumption in Swiss Fattening Pig Farms-A Case-Control Study. Porc. Health Manag. 2016,2 , 5. [CrossRef]

23. Raasch, S.; Postma, M.; Dewulf, J.; Stärk, K.; Beilage, E.G. Association between Antimicrobial Usage, Biosecurity Measures as Well as Farm Performance in German Farrow-to-Finish Farms. Porc. Health Manag. 2018, 4, 30. [CrossRef] [PubMed] 
24. Postma, M.; Backhans, A.; Collineau, L.; Loesken, S.; Sjölund, M.; Belloc, C.; Emanuelson, U.; Beilage, E.G.; Nielsen, E.; Stärk, K.D.; et al. Evaluation of the Relationship between the Biosecurity Status, Production Parameters, Herd Characteristics and Antimicrobial Usage in Farrow-to-Finish Pig Production in Four EU Countries. Porc. Health Manag. 2016, 2, 9. [CrossRef] [PubMed]

25. Laanen, M.; Persoons, D.; Ribbens, S.; de Jong, E.; Callens, B.; Strubbe, M.; Maes, D.; Dewulf, J. Relationship between Biosecurity and Production/Antimicrobial Treatment Characteristics in Pig Herds. Vet. J. 2013, 198, 508-512. [CrossRef]

26. Casal, J.; Mateu, E.; Mejía, W.; Martín, M. Factors Associated with Routine Mass Antimicrobial Usage in Fattening Pig Units in a High Pig-Density Area. Vet. Res. 2007, 38, 481-492. [CrossRef]

27. EMA (European Medicines Agency); EFSA (European Food Safety Authority). EMA and EFSA Joint Scientific Opinion on measures to reduce the need to use antimicrobial agents in animal husbandry in the European Union, and the resulting impacts on food safety (RONAFA). EFSA J. 2017, 15, 4666. [CrossRef]

28. Postma, M.; Stärk, K.; Sjölund, M.; Backhans, A.; Beilage, E.; Lösken, S.; Belloc, C.; Collineau, L.; Iten, D.; Visschers, V.; et al. Alternatives to the Use of Antimicrobial Agents in Pig Production: A Multi-Country Expert-Ranking of Perceived Effectiveness, Feasibility and Return on Investment. Prev. Vet. Med. 2015, 118, 457-466. [CrossRef]

29. Dupont, N.; Diness, L.H.; Fertner, M.; Kristensen, C.S.; Stege, H. Antimicrobial Reduction Measures Applied in Danish Pig Herds Following the Introduction of the "Yellow Card" Antimicrobial Scheme. Prev. Vet. Med. 2017, 138, 9-16. [CrossRef]

30. Coyne, L.A.; Latham, S.M.; Dawson, S.; Donald, I.J.; Pearson, R.B.; Smith, R.F.; Williams, N.J.; Pinchbeck, G.L. Exploring Perspectives on Antimicrobial Use in Livestock: A Mixed-Methods Study of UK Pig Farmers. Front. Vet. Sci. 2019, 6, 257. [CrossRef] [PubMed]

31. Bak, H.; Rathkjen, P.H. Reduced Use of Antimicrobials after Vaccination of Pigs against Porcine Proliferative Enteropathy in a Danish SPF Herd. Acta Vet. Scand. 2009, 51, 1. [CrossRef]

32. Kristensen, C.; Baadsgaard, N.; Toft, N. A Meta-Analysis Comparing the Effect of PCV2 Vaccines on Average Daily Weight Gain and Mortality Rate in Pigs from Weaning to Slaughter. Prev. Vet. Med. 2011, 98, 250-258. [CrossRef] [PubMed]

33. Sacristán, R.D.P.; Michiels, A.; Martens, M.; Haesebrouck, F.; Maes, D. Efficacy of Vaccination against Actinobacillus Pleuropneumoniae in Two Belgian Farrow-to-Finish Pig Herds with a History of Chronic Pleurisy. Vet. Rec. 2014, 174, 302. [CrossRef] [PubMed]

34. Temtem, C.; Kruse, A.; Nielsen, L.; Pedersen, K.; Alban, L. Comparison of the Antimicrobial Consumption in Weaning Pigs in Danish Sow Herds with Different Vaccine Purchase Patterns during 2013. Porc. Health Manag. 2016, 2, 23. [CrossRef] [PubMed]

35. Kruse, A.; Kristensen, C.; Nielsen, L.; Alban, L. A Register-Based Study on Associations between Vaccination, Antimicrobial Use and Productivity in Conventional Danish Finisher Pig Herds during 2011 to 2014. Prev. Vet. Med. 2019, 164, 33-40. [CrossRef]

36. Backhans, A.; Sjölund, M.; Lindberg, A.; Emanuelson, U. Antimicrobial Use in Swedish Farrow-to-Finish Pig Herds Is Related to Farmer Characteristics. Porc. Health Manag. 2016, 2, 18. [CrossRef] [PubMed]

37. Visschers, V.; Postma, M.; Sjölund, M.; Backhans, A.; Collineau, L.; Loesken, S.; Belloc, C.; Dewulf, J.; Emanuelson, U.; Beilage, G.E.; et al. Higher Perceived Risk of Antimicrobials Is Related to Lower Antimicrobial Usage among Pig Farmers in Four European Countries. Vet. Rec. 2016, 179, 490. [CrossRef]

38. Moreno, M.A. Opinions of Spanish Pig Producers on the Role, the Level and the Risk to Public Health of Antimicrobial Use in Pigs. Res. Vet. Sci. 2014, 97, 26-31. [CrossRef] [PubMed]

39. Visschers, V.H.M.; Backhans, A.; Collineau, L.; Iten, D.; Loesken, S.; Postma, M.; Belloc, C.; Dewulf, J.; Emanuelson, U.; Grosee Beilage, E.; et al. Perceptions of Antimicrobial Usage, Antimicrobial Resistance and Policy Measures to Reduce Antimicrobial Usage in Convenient Samples of Belgian, French, German, Swedish and Swiss Pig Farmers. Prev. Vet. Med. 2015, 119, 10-20. [CrossRef] [PubMed]

40. Diana, A.; Snijders, S.; Rieple, A.; Boyle, L. Why Do Irish Pig Farmers Use Medications? Barriers for Effective Reduction of Antimicrobials in Irish Pig Production. Ir. Vet. J. 2021, 74, 12. [CrossRef]

41. Ström, G.; Boqvist, S.; Albihn, A.; Fernström, L.-L.; Djurfeldt, A.A.; Sokerya, S.; Sothyra, T.; Magnusson, U. Antimicrobials in Small-Scale Urban Pig Farming in a Lower Middle-Income Country-Arbitrary Use and High Resistance Levels. Antimicrob. Resist. Infect. Control 2018, 7, 35. [CrossRef] [PubMed]

42. Isomura, R.; Matsuda, M.; Sugiura, K. An Epidemiological Analysis of the Level of Biosecurity and Animal Welfare on Pig Farms in Japan and Their Effect on the Use of Veterinary Antimicrobials. J. Vet. Med. Sci. 2018, 80, 18-0287. [CrossRef]

43. Danish Veterinary and Food Administration. Guideline for Prescribing Antimicrobial for Pigs. 2018. Available online: https://www.foedevarestyrelsen.dk/english/Animal/AnimalHealth/Veterinary_medicine/Documents/Antimicrobial\%20 guideline\%20for\%20pigs\%20Denmark\%202018.pdf (accessed on 23 August 2021).

44. AMCRA. Vade-Mecum Pour Un Usage Responsable Des Produits Antibacteriens Chez Les Porcs. 2021. Available online: https:/ / formularium.amcra.be/a/3 (accessed on 23 August 2021).

45. Jensen, V.F.; Jorsal, S.-E.L.; Toft, N. A Cross-Sectional Study of Oral Antibacterial Treatment Patterns in Relation to Specific Diarrhoeal Pathogens in Weaner Pigs. Vet. Microbiol. 2017, 203, 18-27. [CrossRef]

46. Sarrazin, S. Analysis of herd level antimicrobial usage in pigs and poultry in 9 European countries based on EFFORT data. Presented to Quantification, Benchmarking and Stewardship of Veterinary Antimicrobial Usage. In Proceedings of the First International Conference, Ghent University, Ghent, Belgium, 27 February 2018; Available online: https: / / aacting.org/first-aacti ng-conference/ (accessed on 4 July 2021). 
47. O’Neill, L.; da Costa, M.; Leonard, F.C.; Gibbons, J.; Díaz, J.; McCutcheon, G.; Manzanilla, E. Quantification, Description and International Comparison of Antimicrobial Use on Irish Pig Farms. Porc. Heal Manag. 2020, 6, 30. [CrossRef]

48. Central Statistics Office (CSO). Pig Survey June 2017. 2017. Available online: https://www.cso.ie/en/releasesandpublications/er /ps/pigsurveyjune2017/ (accessed on 2 December 2020).

49. Timmerman, T.; Dewulf, J.; Catry, B.; Feyen, B.; Opsomer, G.; de Kruif, A.; Maes, D. Quantification and Evaluation of Antimicrobial Drug Use in Group Treatments for Fattening Pigs in Belgium. Prev. Vet. Med. 2006, 74, 251-263. [CrossRef]

50. European Medicines Agency. Defined Daily Doses for Animals (DDDvet) and Defined Course Doses for Animals (DCDvet) European Surveillance of Veterinary Antimicrobial Consumption (ESVAC). 2016. Available online: https://www.ema.europa.eu/en/d ocuments / other/defined-daily-doses-animalsdddvet-defined-course-doses-animals-dcdvet-european-surveillance_en.pdf (accessed on 20 March 2020).

51. European Medicine Agency. Revised ESVAC Reflection Paper on Collecting Data on Consumption of Antimicrobial Agents per Animal Species, on Technical Units of Measurement and Indicators for Reporting Consumption of Antimicrobial Agents in Animals. 2013. Available online: https://www.ema.europa.eu/documents/scientific-guideline/revised-europeansurveillanc e-veterinary-antimicrobial-consumption-esvac-reflection-papercollecting_en.pdf (accessed on 2 August 2019).

52. Rodrigues da Costa, M.; Gasa, J.; Díaz, J.A.C.; Postma, M.; Dewulf, J.; McCutcheon, G.; Manzanilla, E.G. Using the Biocheck.UGent ${ }^{\mathrm{TM}}$ Scoring Tool in Irish Farrow-to-Finish Pig Farms: Assessing Biosecurity and Its Relation to Productive Performance. Porc. Health Manag. 2019, 5, 4. [CrossRef]

53. Rodrigues da Costa, M.; Fitzgerald, R.; Manzanilla, E.; O'Shea, H.; Moriarty, J.; McElroy, M.C.; Leonard, F. A Cross-Sectional Survey on Respiratory Disease in a Cohort of Irish Pig Farms. Ir. Vet. J. 2020, 73, 24. [CrossRef]

54. Madec, F.; Derrien, H. Fréquence, intensité et localisation des lésions pulmonaires chez le porc charcutier: Résultats d'une premiére série d'observations en abattoir. Journées Rech. Porc. Fr. 1981, 13, 231-236.

55. Dottori, M.; Nigrelli, A.D.; Bonilauri, P.; Merialdi, G.; Gozio, S.; Cominotti, F. Proposta Di Un Nuovo Sistema Di Punteggiatura Delle Pleuriti Suine in Sede Di Macellazione. La Griglia, S.P.E.S. (Slaughterhouse Pleuritis Evaluation System) O. Large Anim. Rev. 2007, 13, 161-165.

56. Merialdi, G.; Dottori, M.; Bonilauri, P.; Luppi, A.; Gozio, S.; Pozzi, P.; Spaggiari, B.; Martelli, P. Survey of Pleuritis and Pulmonary Lesions in Pigs at Abattoir with a Focus on the Extent of the Condition and Herd Risk Factors. Vet. J. 2012, 193, 234-239. [CrossRef]

57. Robinson, N.A.; Loynachan, A.T. Cardiovascular and Hematopoietic Systems. In Diseases of Swine, 11th ed.; Zimmerman, J.J., Karriker, L.A., Ramirez, A., Schwartz, K.J., Stevenson, G.W., Zhang, J., Eds.; John Wiley and Sons, Inc.: Hoboken, NJ, USA, 2019; pp. 221-233. ISBN 9781119350927. [CrossRef]

58. Thomson, J.R.; Friendship, R.M. Digestive system. In Diseases of Swine, 11th ed.; Zimmerman, J.J., Karriker, L.A., Ramirez, A., Schwartz, K.J., Stevenson, G.W., Zhang, J., Eds.; John Wiley and Sons, Inc.: Hoboken, NJ, USA, 2019; pp. 234-263. ISBN 9781119350927. [CrossRef]

59. R Core Team. R: A Language and Environment for Statistical Computing; R Foundation for Statistical Computing: Vienna, Austria, 2017; Available online: https: / / www.R-project.org/ (accessed on 20 November 2020).

60. Wickham, H. ggplot2: Elegant Graphics for Data Analysis; Springer: New York, NY, USA, 2016; Available online: https:/ /ggplot2.ti dyverse.org (accessed on 4 March 2021).

61. Hanbo Chen. VennDiagram: Generate High-Resolution Venn and Euler Plots. R Package Version 1.6.20. 2018. Available online: https: / /CRAN.R-project.org/package=VennDiagram (accessed on 4 March 2021).

62. Marquer, P.; Rabade, T.; Forti, R. Pig farming in the European Union: Considerable variations from one member state to another. Eurostat Statis Focus. 2014, 15,1-13. Available online: https:/ / ec.europa.eu/eurostat/statistics-explained/index.php?title=Archi ve:Pig_farming_sector___statistical_portrait_2014 (accessed on 26 September 2021).

63. World Health Organization (WHO). Critically Important Antimicrobials for Human Medicine, 6th Revision 2018. World Health Organization: Geneva, Switzerland, 2019. Available online: https://apps.who.int/iris/bitstream/handle/10665/312266/978924 1515528-eng.pdf?ua=1 (accessed on 1 April 2020).

64. European Medicines Agency. Categorisation of Antibiotics for Use in Animals for Prudent and Responsible Use. 2019. Available online: https: / / www.ema.europa.eu/en/documents/report/categorisation-antibiotics-use-animalsprudent-responsible-use_ en.pdf (accessed on 2 February 2020).

65. Regulation (EU) 2019/4 of the European Parliament and of the Council of 11 December 2018 on the Manufacture, Placing on the Market and Use of Medicated Feed, Amending Regulation (EC) No 183/2005 of the European Parliament and of the Council and Repealing Council Directive 90/167/EEC (Text with EEA Relevance). 2019, pp. 1-23. Available online: http:/ / data.europa.eu/eli/reg/2019/4/oj (accessed on 2 July 2021).

66. Rodrigues da Costa, M. Evaluation of Current Feeding and Management Practices in Irish Pig Production and Future Strategies for Improvement. Ph.D. Thesis, Universitat Autònoma de Barcelona, Barcelona, Spain, 2018. Available online: http://hdl.handle .net/10803/666618 (accessed on 3 March 2021).

67. Stege, H.; Jensen, T.K.; Møller, K.; Bækbo, P.; Jorsal, S.E. Risk Factors for Intestinal Pathogens in Danish Finishing Pig Herds. Prev. Vet. Med. 2001, 50, 153-164. [CrossRef]

68. Campbell, J.M.; Crenshaw, J.D.; Polo, J. The Biological Stress of Early Weaned Piglets. J Anim. Sci. Biotechnol. 2013, 4, 19. [CrossRef] 
69. Moeser, A.J.; Pohl, C.S.; Rajput, M. Weaning Stress and Gastrointestinal Barrier Development: Implications for Lifelong Gut Health in Pigs. Anim. Nutr. 2017, 3, 313-321. [CrossRef] [PubMed]

70. Gebhardt, J.T.; Tokach, M.D.; Dritz, S.S.; DeRouchey, J.M.; Woodworth, J.C.; Goodband, R.D.; Henry, S.C. Postweaning Mortality in Commercial Swine Production II: Review of Infectious Contributing Factors. Transl. Anim. Sci. 2020, 4, txaa052. [CrossRef] [PubMed]

71. Gebhardt, J.T.; Tokach, M.D.; Dritz, S.S.; DeRouchey, J.M.; Woodworth, J.C.; Goodband, R.D.; Henry, S.C. Postweaning Mortality in Commercial Swine Production. I: Review of Non-Infectious Contributing Factors. Transl. Anim. Sci. 2020, 4, txaa068. [CrossRef] [PubMed]

72. Stevens, K.; Gilbert, J.; Strachan, W.; Robertson, J.; Johnston, A.; Pfeiffer, D. Characteristics of Commercial Pig Farms in Great Britain and Their Use of Antimicrobials. Vet. Rec. 2007, 161, 45. [CrossRef] [PubMed]

73. Scali, F.; Santucci, G.; Maisano, A.M.; Giudici, F.; Guadagno, F.; Tonni, M.; Amicabile, A.; Formenti, N.; Giacomini, E.; Lazzaro, M.; et al. The Use of Antimicrobials in Italian Heavy Pig Fattening Farms. Antibiotics 2020, 9, 892. [CrossRef]

74. Filippitzi, M.; Kruse, B.A.; Postma, M.; Sarrazin, S.; Maes, D.; Alban, L.; Nielsen, L.; Dewulf, J. Review of Transmission Routes of 24 Infectious Diseases Preventable by Biosecurity Measures and Comparison of the Implementation of These Measures in Pig Herds in Six European Countries. Transbound. Emerg. Dis. 2018, 65, 381-398. [CrossRef]

75. Collineau, L.; Rojo-Gimeno, C.; Léger, A.; Backhans, A.; Loesken, S.; Nielsen, E.O.; Postma, M.; Emanuelson, U.; Beilage, E.; Sjölund, M.; et al. Herd-Specific Interventions to Reduce Antimicrobial Usage in Pig Production without Jeopardising Technical and Economic Performance. Prev. Vet. Med. 2017, 144, 167-178. [CrossRef] [PubMed]

76. Raasch, S.; Collineau, L.; Postma, M.; Backhans, A.; Sjölund, M.; Belloc, C.; Emanuelson, U.; Beilage, E.; Stärk, K.; Dewulf, J.; et al. Effectiveness of Alternative Measures to Reduce Antimicrobial Usage in Pig Production in Four European Countries. Porc. Heal. Manag. 2020, 6, 6. [CrossRef] [PubMed]

77. USDA. Swine 2012: Part I: Baseline Reference of Swine Health and Management in the United States, 2012. USDA-APHIS-VS, CEAH, Fort Collins, CO. 2015; \#663.0814. Available online: https://www.aphis.usda.gov/animal_health/nahms/swine/downl oads/swine2012/Swine2012_dr_PartI.pdf (accessed on 16 March 2021).

78. Yaeger, M.J.; Alstine, W.G. Respiratory system. In Diseases of Swine, 11th ed.; Zimmerman, J.J., Karriker, L.A., Ramirez, A., Schwartz, K.J., Stevenson, G.W., Zhang, J., Eds.; John Wiley and Sons, Inc.: Hoboken, NJ, USA, 2019; pp. 393-407, ISBN 9781119350927. [CrossRef]

79. Gottschalk, M.; Segura, M. Streptococcosis. In Diseases of Swine, 11th ed.; Zimmerman, J.J., Karriker, L.A., Ramirez, A., Schwartz, K.J., Stevenson, G.W., Zhang, J., Eds.; John Wiley and Sons, Inc.: Hoboken, NJ, USA, 2019; pp. 934-950, ISBN 9781119350927. [CrossRef]

80. Aragon, V.; Segales, J.; Tucker, A.W. Glässer's disease. In Diseases of Swine, 11th ed.; Zimmerman, J.J., Karriker, L.A., Ramirez, A., Schwartz, K.J., Stevenson, G.W., Zhang, J., Eds.; John Wiley and Sons, Inc.: Hoboken, NJ, USA, 2019; pp. 844-853, ISBN 9781119350927. [CrossRef]

81. Steenhard, N.R.; Jungersen, G.; Kokotovic, B.; Beshah, E.; Dawson, H.D.; Urban, J.F.; Roepstorff, A.; Thamsborg, S.M. Ascaris suum Infection Negatively Affects the Response to a Mycoplasma Hyopneumoniae Vaccination and Subsequent Challenge Infection in Pigs. Vaccine 2009, 27, 5161-5169. [CrossRef] [PubMed]

82. Callens, B.; Persoons, D.; Maes, D.; Laanen, M.; Postma, M.; Boyen, F.; Haesebrouck, F.; Butaye, P.; Catry, B.; Dewulf, J. Prophylactic and Metaphylactic Antimicrobial Use in Belgian Fattening Pig Herds. Prev. Vet. Med. 2012, 106, 53-62. [CrossRef] [PubMed]

83. Cameron-Veas, K.; Solà-Ginés, M.; Moreno, M.A.; Fraile, L.; Migura-Garcia, L. Impact of the Use of $\beta$-Lactam Antimicrobials on the Emergence of Escherichia Coli Isolates Resistant to Cephalosporins under Standard Pig-Rearing Conditions. Appl. Environ. Microbiol. 2015, 81, 1782-1787. [CrossRef]

84. Kruse, A.B.; Knegt, L.V.; de Nielsen, L.R.; Alban, L. No Clear Effect of Initiating Vaccination against Common Endemic Infections on the Amounts of Prescribed Antimicrobials for Danish Weaner and Finishing Pigs during 2007-2013. Front. Vet. Sci. 2017, 3, 120. [CrossRef]

85. Holt, H.R.; Alarcon, P.; Velasova, M.; Pfeiffer, D.U.; Wieland, B. BPEX Pig Health Scheme: A Useful Monitoring System for Respiratory Disease Control in Pig Farms? BMC Vet. Res. 2011, 7, 82. [CrossRef]

86. Opriessnig, T.; Giménez-Lirola, L.; Halbur, P. Polymicrobial Respiratory Disease in Pigs. Anim. Health Res. Rev. 2011, 12, 133-148. [CrossRef]

87. Díaz, J.A.C.; Fitzgerald, R.M.; Shalloo, L.; da Costa, M.R.; Niemi, J.; Leonard, F.C.; Kyriazakis, I.; Manzanilla, E.G. Financial Analysis of Herd Status and Vaccination Practices for Porcine Reproductive and Respiratory Syndrome Virus, Swine Influenza Virus, and Mycoplasma Hyopneumoniae in Farrow-to-Finish Pig Farms Using a Bio-Economic Simulation Model. Front. Vet. Sci. 2020, 7, 556674. [CrossRef]

88. Regulation (EU). 2019/6 of the European Parliament and of the Council of 11 December 2018 on Veterinary Medicinal Products and Repealing Directive 2001/82/EC (Text with EEA Relevance). 2019, pp. 43-167. Available online: http:/ / data.europa.eu/eli / reg/2019/6/oj (accessed on 4 April 2020).

89. UK-VARSS. UK Veterinary Antibiotic Resistance and Sales Surveillance Report (UK-VARSS 2019). Veterinary Medicines Directorate. 2020. Available online: https:/ / assets.publishing.service.gov.uk/government/uploads/system/uploads/attachment_ data/file/950126/UK-VARSS_2019_Report_2020-TPaccessible.pdf (accessed on 20 December 2020).

90. Aarestrup, F. Sustainable Farming: Get Pigs off Antibiotics. Nature 2012, 486, 465-466. [CrossRef] 
91. Speksnijder, D.; Mevius, D.; Bruschke, C.; Wagenaar, J. Reduction of Veterinary Antimicrobial Use in the Netherlands. The Dutch Success Model. Zoonoses Public Health 2015, 62, 79-87. [CrossRef]

92. Rojo-Gimeno, C.; Postma, M.; Dewulf, J.; Hogeveen, H.; Lauwers, L.; Wauters, E. Farm-Economic Analysis of Reducing Antimicrobial Use Whilst Adopting Improved Management Strategies on Farrow-to-Finish Pig Farms. Prev. Vet. Med. 2016, 129, 74-87. [CrossRef]

93. Postma, M.; Vanderhaeghen, W.; Sarrazin, S.; Maes, D.; Dewulf, J. Reducing Antimicrobial Usage in Pig Production without Jeopardizing Production Parameters. Zoonoses Public Health 2017, 64, 63-74. [CrossRef] [PubMed]

94. Diana, A.; Boyle, L.A.; Leonard, F.C.; Carroll, C.; Sheehan, E.; Murphy, D.; Manzanilla, E.G. Removing Prophylactic Antibiotics from Pig Feed: How Does It Affect Their Performance and Health? BMC Vet. Res. 2019, 15, 67. [CrossRef] [PubMed]

95. European Commission. Commission Implementing Decision of 26.6.2017 Concerning, in the Framework of Article 35 of Directive 2001/82/EC of the European Parliament and of the Council, the Marketing Authorisations for Veterinary Medicinal Products Containing "Zinc Oxide" to be Administered Orally to Food Producing Species. 2017. Available online: https: / / ec.europa.eu/health/documents / community-register/2017/20170626136754/dec_136754_en.pdf (accessed on 16 September 2021).

96. Nielsen, C.; Kongsted, H.; Sørensen, J.; Krogh, M. Antibiotic and Medical Zinc Oxide Usage in Danish Conventional and Welfare-Label Pig Herds in 2016-2018. Prev Vet Med 2021, 189, 105283. [CrossRef] [PubMed]

97. Maes, D.; Deluyker, H.; Verdonck, M.; Kruif, A.; Ducatelle, R.; Castryck, F.; Miry, C.; Vrijens, B. Non-infectious Factors Associated with Macroscopic and Microscopic Lung Lesions in Slaughter Pigs from Farrow-to-finish Herds. Vet. Rec. 2001, 148, 41-46. [CrossRef] [PubMed]

98. Agostini, P.; Fahey, A.; Manzanilla, E.; O’Doherty, J.; de Blas, C.; Gasa, J. Management Factors Affecting Mortality, Feed Intake and Feed Conversion Ratio of Grow-Finishing Pigs. Animal 2014, 8, 1312-1318. [CrossRef] 